\title{
ESTIMATION OF RECTAL TEMPERATURE OF GOATS BASED ON SURFACE TEMPERATURE
}

\author{
Jordânio I. Marques ${ }^{1 *}$, Patrício G. Leite ${ }^{1}$, José P. Lopes Neto ${ }^{2}$, \\ Dermeval A. Furtado², Fernanda F. de M. Lopes ${ }^{3}$
}

${ }^{1 *}$ Corresponding author. Universidade Federal do Maranhão/ Chapadinha - MA, Brasil.
E-mail: jordanio.marques@ufma.br | ORCID ID: http://orcid.org/0000-0002-7665-8218

\section{KEYWORDS \\ Bland-Altman, concordance, thermal stress, thermography.}

\begin{abstract}
Infrared thermography (IR) is a non-invasive tool with potential to indicate changes in the animal's thermal conditions in response to the thermally stressful environment. The objective of this study was to evaluate the application of IR to estimate the rectal temperature of crossbred goats of the Boer breed. Six male crossbred goats of the Boer breed were distributed in a completely randomized design and submitted to temperatures of 26,30 and $34{ }^{\circ} \mathrm{C}$. Rectal temperature (RT) and thermograms data were collected from animals at each air temperature evaluated. In the thermograms, the temperatures of the ocular globe (PT), head (HT), shoulder (ST), hindquarter (HQ) and maximum infrared $\left(\mathrm{IR}_{\mathrm{Max}}\right)$ of the animals' surfaces were collected, the latter being observed in the lower region of the animals' eyes, at all air temperatures evaluated. The correlation of PT, HT,

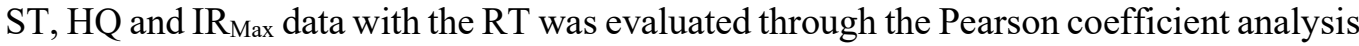
and the concordance using Bland-Altman diagrams. With the exception of the $\mathrm{IR}_{\mathrm{Max}}$ surface temperature, the others were adequate for the accurate estimation of RT, with PT standing out for presenting the highest correlation coefficient with RT $(r=0.951)$ and estimation errors varying in the range of $\pm 0.27^{\circ} \mathrm{C}$.
\end{abstract}

\section{INTRODUCTION}

The exploration of beef goats is a potential activity, especially in arid and semi-arid regions, because they are rustic animals and adapted to the specific climatic conditions of these regions. However, when they are exposed to high air temperatures, their production potential is reduced due to stimuli of the peripheral receptors and the corporeal nucleus that are sent to the specific centers of the hypothalamus for the activation of evaporative and nonevaporative cooling systems altering the operation of the appetite control center. The suppressive impulses transmitted to the center of the appetite cause a decrease in food intake. Thus, fewer substrates are available for enzymatic activities, hormone synthesis and heat production which helps to cool the body thus reducing animal production efficiency (Sejian et al., 2018).

The evaluation of the thermal state of animals destined for commercial exploration is usually done by rectal thermometry, where it is adopted as the representative temperature of the body core. The increase in rectal temperature indicates that thermoregulatory mechanisms are not being efficient for the dissipation of metabolic heat produced, this method in most cases requires that the animals be handled directly by the experimenter. This method is laborious and may influences animals' behavior, which in turn affects the thermoregulatory responses (Byrne et al., 2017). According to McManus et al. (2016) there are non-invasive methods that can be used to evaluate the thermal state of the animals. Among the existing methods, infrared thermography (IR) can be highlighted that has good precision and dispenses direct contact with the individuals, thus presenting a high potential both for the development of research as for the monitoring of animals at the farm.

The IR measures the thermal radiation of the animal's surface and translates this to surface temperature. Comparing the rectal and IR thermometry methods, the two are distinct not only in the technique, where the rectal

\footnotetext{
${ }^{1}$ Universidade Federal do Maranhão/ Chapadinha - MA, Brasil.

${ }^{2}$ Universidade Federal de Campina Grande/ Campina Grande - PB, Brasil.

${ }^{3}$ Universidade Federal da Paraíba/ Areia - PB, Brasil.
} 
thermometry is based on the transfer of conductive heat to the sensor, while the thermographic equipment measures the radiation. In addition, thermography measures the temperature at the surface of the body, which is constantly involved in heat exchanges with the environment, while temperature of the rectal cavity depends on the thermal situation of the body core (George et al., 2014).

The objective of this study was to evaluate the application of IR to estimate the rectal temperature of crossbred $3 / 4$ Boer $+1 / 4$ goats with no defined racial pattern.

\section{MATERIAL AND METHODS}

\section{Animals and housing}

Six male crossbred goats $(3 / 4$ Boer breed and $1 / 4$ no defined racial pattern (NDRP)) were selected from breeding herds suitable for meat production, with an average weight of $25.06 \pm 4.43 \mathrm{~kg}$ and mean age of six months of white color with brown head, were kept in a climatic chamber (EOS $\AA$, TR-18, Minas Gerais, Brazil, temperature range $15.0-50.0^{\circ} \mathrm{C}$ and accuracy of $\pm 1.0^{\circ} \mathrm{C}$ ), with dimensions of the $6.14 \times 2.77 \times 2.60 \mathrm{~m}$ width, length, and height, respectively) and housed individually in stalls with dimensions of $1.15 \times 0.50 \times 0.84 \mathrm{~m}$ (length, width, and height, respectively).

\section{Experimental design}

The animals were distributed in a completely randomized design with three treatments (air temperatures) and six replicates (animals). The air temperatures used in the experiment were determined based on the thermal comfort zone (ZCT) for goats mentioned by Souza et al. (2008), which is between 20 and $30{ }^{\circ} \mathrm{C}$, with relative humidity of between 50 and $70 \%$. Thus, the animals were submitted to the three different average temperatures controlled: T26 $=26{ }^{\circ} \mathrm{C}$ (thermal comfort zone), T30 $=30^{\circ} \mathrm{C}$ (temperature limit between comfort zone and thermal stress) and $\mathrm{T} 34=34{ }^{\circ} \mathrm{C}$ (above ZCT), with relative humidity and wind speed averages of $68 \% \pm 4 \%$ and $1 \mathrm{~m} / \mathrm{s}$, respectively.

\section{Experimental procedures}

For each thermal condition studied, a period of five days was used to adapt the animals to the controlled environment, as well as handling and feeding. Data were collected within 10 days for each treatment. In the interval

(A)

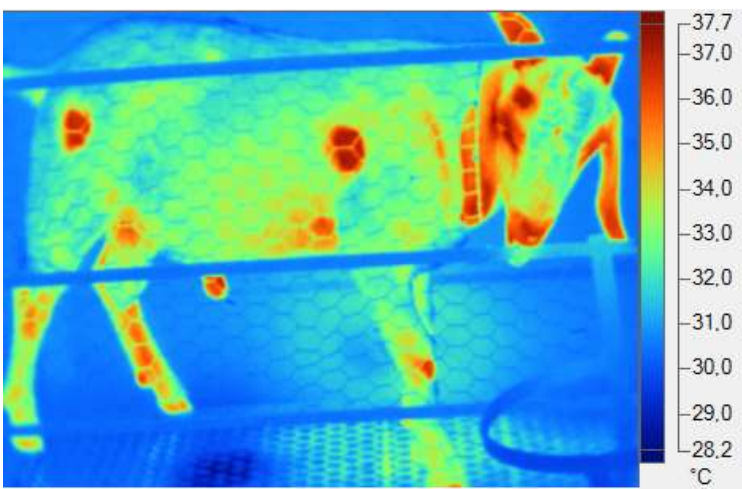

between treatments, the animals were exposed to the temperature and relative humidity of the ambient air (with the open chamber) for the restoration of their physiological functions, for five days.

As suggested by Lopes Neto et al. (2018) and Marques et al. (2018), at each stage of study in the climatic chamber, the animals were submitted to a cycle of $8 / 16 \mathrm{~h}$ (experimental air temperature / ambient air temperature). The chamber was turned on each day at 7 a.m., allowing 1 $\mathrm{h}$ to stabilize the air temperature and internal relative humidity. Following stabilization, the experimental period began at 8 a.m., with the animals remaining inside the closed chamber until 4 p.m.

Animal feed and water were provided ad libitum. The feed supplied to the animals consisted of Tifton hay (Cynodon dactylon (L) Pers), which was $43.0 \%$ of the total volume of the feed, as well as corn meal $(26.6 \%)$, molasses $(2.5 \%)$ soybean oil $(2.0 \%)$, mineral salt $(1.5 \%)$ and calcitic limestone $(0.4 \%)$, according to the composition indicated by NRC (2007) and adopted by Marques et al. (2018).

\section{Data collect}

The thermograms and rectal temperature (RT) were acquired on the third, sixth and ninth days after the start of each experimental phase, always at the same time, at 10:00 a.m. The RT was collected manually by inserting a digital thermometer (Incoterm, Med flex, Digital Thermometer, Rio Grande do Sul, Brazil, variation of $32 \sim 43{ }^{\circ} \mathrm{C}$ and accuracy of $\pm 0,20^{\circ} \mathrm{C}$ ) $\sim 2 \mathrm{~cm}$ in the rectum of each animal with the bulb in contact with the mucosa.

For the acquisition of the thermograms (Figure 1A), a thermographic camera model Ti55FT $(60 \mathrm{~Hz}$, firmware version v.1.22, 320x240, accuracy $\pm 2{ }^{\circ} \mathrm{C}$, Fluke ${ }^{\circledR}$, Washington, USA) was used. In the thermograms, it was collected the mean infrared temperature of the ocular globe (PT) and of the skin surface were evaluated in the regions of the head (HT), shoulder (ST) and hindquarters (HQ) that were previously depilated, as shown in Figure 1B. In addition to the temperatures mentioned, the maximum infrared temperature $\left(\mathrm{IR}_{\mathrm{Max}}\right)$ was also evaluated, corresponding to the pixel with the highest temperature found in the thermograms of the animals, which was identified in the lower region of the ocular mucosa, in all animals and treatments evaluated.

(B)

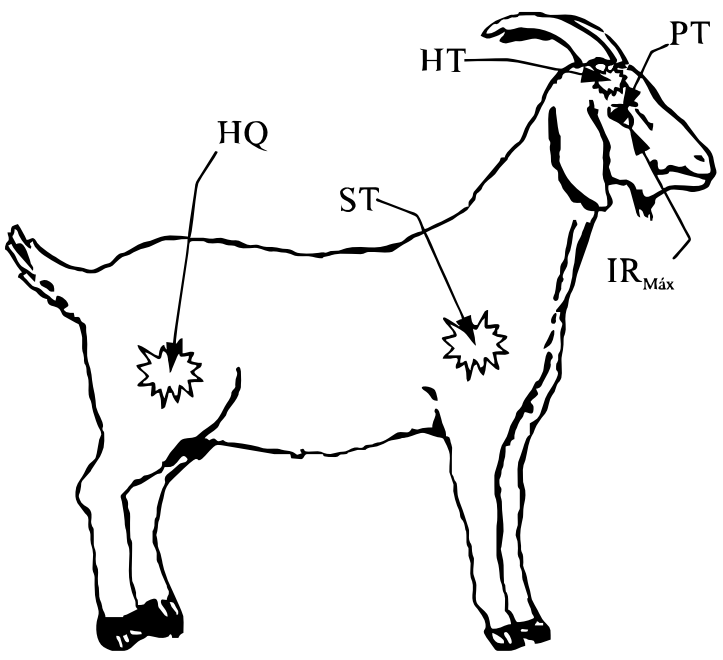

FIGURE 1. (A) Thermogram of one of the animals evaluated; and a (B) Experimental configuration of the collection points of the animal's surface temperatures, which are: ocular globe (PT), head (HT), shoulder (ST), hindquarters (HQ) and maximum infrared temperature $\left(\mathrm{IR}_{\mathrm{Max}}\right)$. 
Three thermograms of each animal were selected, obtained at each air temperature tested for the analysis of the regions under study. Emissivity was adjusted to 0.98 , based on data for humans (Steketee, 1973), taking into account that the evaluated regions were absent of hair and that the characteristics of the skin are similar between humans and the animals evaluated. The distance to the targets was $\sim 2 \mathrm{~m}$, allowing a complete view of the animals, from the snout to the tail.

\section{Statistical analysis}

The data were presented in box diagrams (boxplot). The normality of the data was verified using the ShapiroWilk test and, subsequently, the data were analyzed using the analysis of variance (ANOVA) and F test, using the ExpDes.pt package (Ferreira et al., 2013) of statistical software $\mathrm{R}$ version 3.4.1. The Tukey test was used to compare the averages, assuming a probability of error of $5 \%$ $(\mathrm{P}<0.05)$.

The correlations between PT, HT, ST, HQ and IR Max $_{\text {M }}$ data with RT were analyzed using simple linear regressions, with a $95 \%$ confidence interval and by assessing the degree of elevation of Pearson's correlation coefficient.

The occurrence of agreement between the evaluated methods was verified using the t-test for paired samples (one sample t-test) $(\mathrm{P}<0.05)$, applied in the differences between of the thermogram and RT measurements. In addition, Bland-Altman diagrams were generated in order to assess the differences between the compared methods, according to the increase in air temperature. The agreement limits were determined by calculating the average of the differences (bias, $\bar{d}$ ) and their standard deviation $(S d)$, these limits being calculated as follows: $\bar{d} \pm 1.96 * S d$. The possibility of occurrence of systematic and random errors in the prediction of RT by the IR method was evaluated, for this, the verification of the occurrence or not of significant bias correlation with the mean of their respective measures was performed.

\section{RESULTS AND DISCUSSION}

\section{Physiological responses}

The effect of increasing air temperature on the RT, PT, HT, ST, HQ and IR $_{\text {Max }}$ responses, respectively, is shown in Figure 2. It can be observed a significant increase $(\mathrm{P}<$ 0.05 ) in all physiological responses as a function of elevation of the air temperature from 26 to 30 and subsequently to $34{ }^{\circ} \mathrm{C}$.

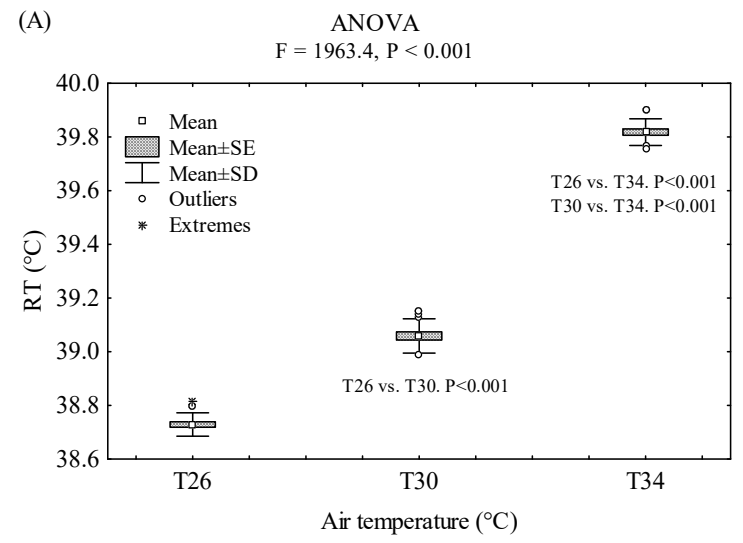

(B)

ANOVA
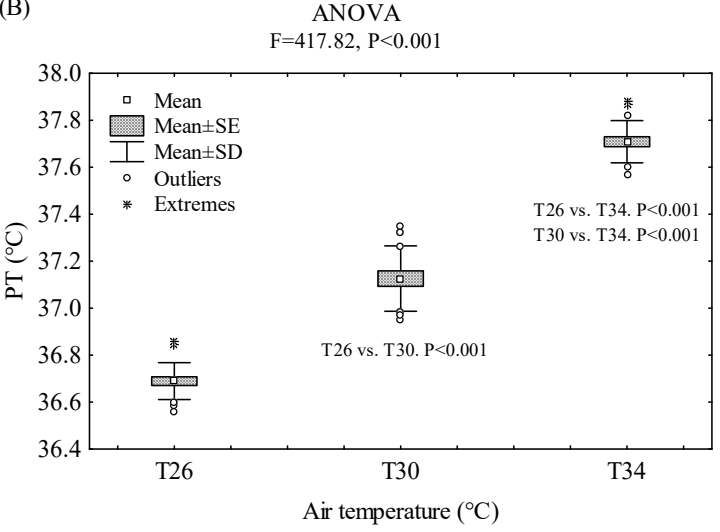

(C)

ANOVA

(D)

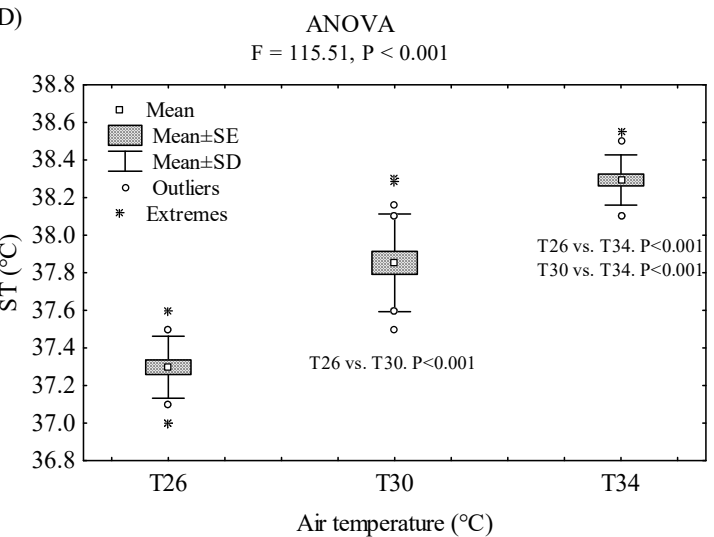



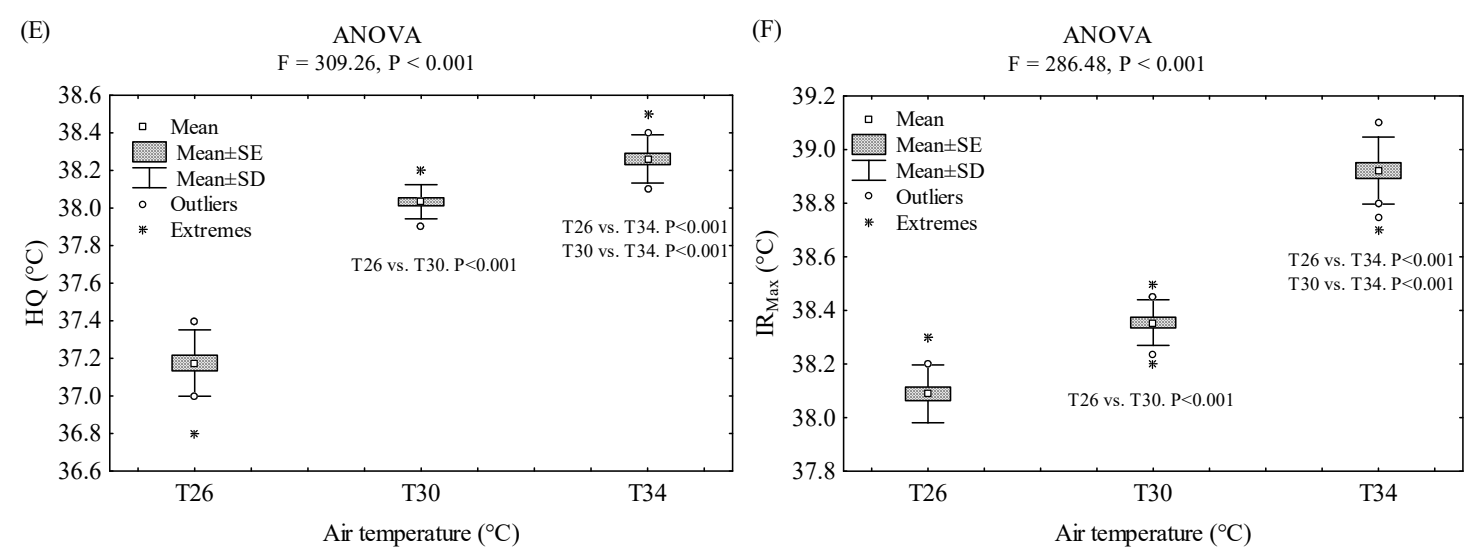

FIGURE 2. Effect of air temperature on physiological responses: (A) rectal temperature - RT; (B) ocular globe temperature PT; (C) head temperature - HT; (D) shoulder temperature - ST; (E) hindquarters temperature - HQ; and (F) maximum infrared temperature - IR $\mathrm{IMx}_{\mathrm{Max}}$ SE: standard error; and SD: standard deviation.

\section{Correlation between of the methods}

The correlations between the physiological response RT and the temperatures PT, HT, ST, HQ and $\mathrm{IR}_{\mathrm{Max}}$, according to the elevation of the air temperature are presented in Figure 3 with a confidence interval of $95 \%$. All

(A)

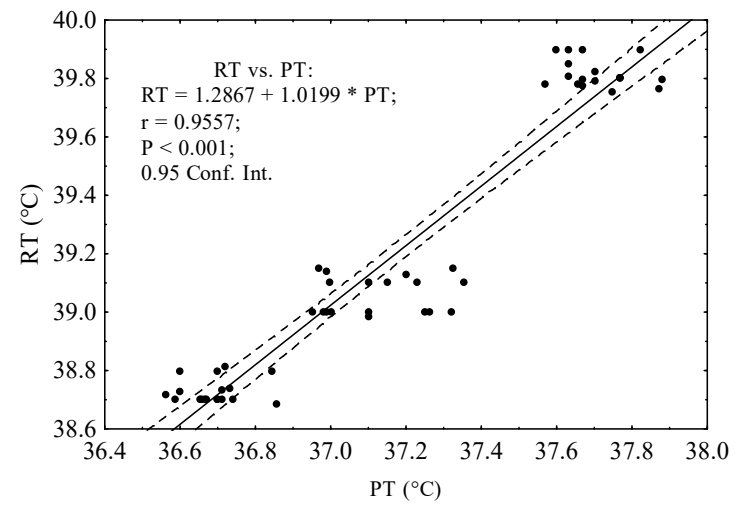

(C)

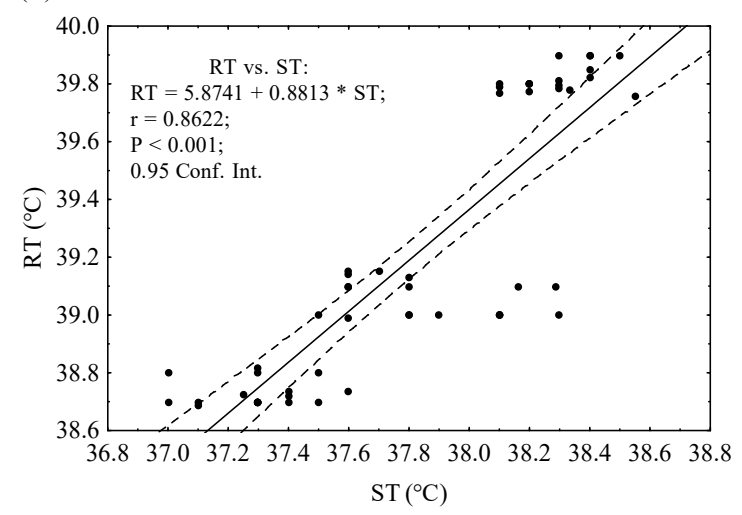

the evaluated responses had a significant positive correlation $(\mathrm{P}<0.05)$ with the RT, with a Pearson correlation coefficient of $0.956,0.904,0.862,0.824$ and 0.951 for PT, HT, ST, HQ and $\mathrm{IR}_{\text {Max }}$, respectively. The physiological responses $\mathrm{PT}$ and $\mathrm{IR}_{\mathrm{Max}}$ as being the ones with the highest correlations with RT.

(B)

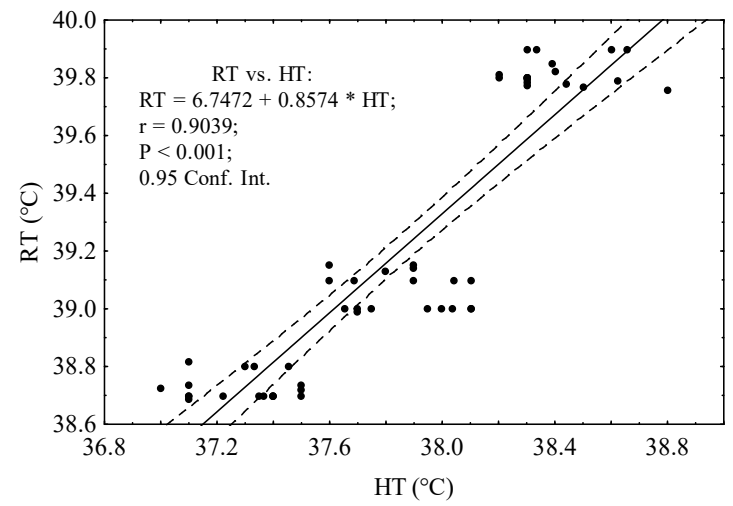

(D)

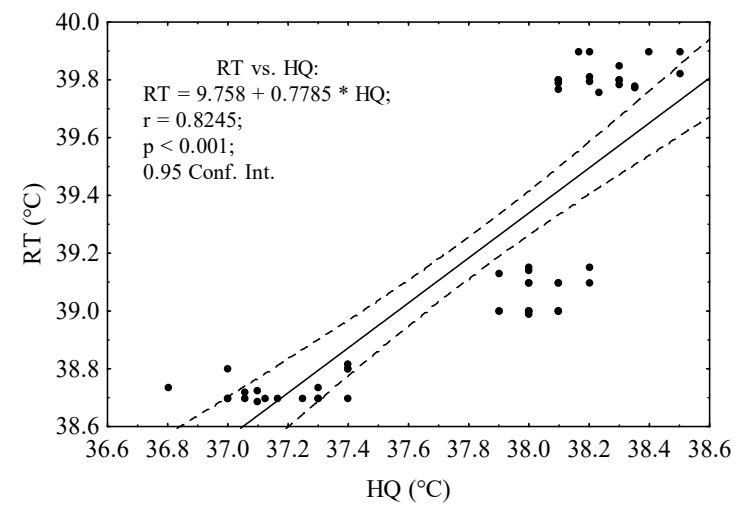




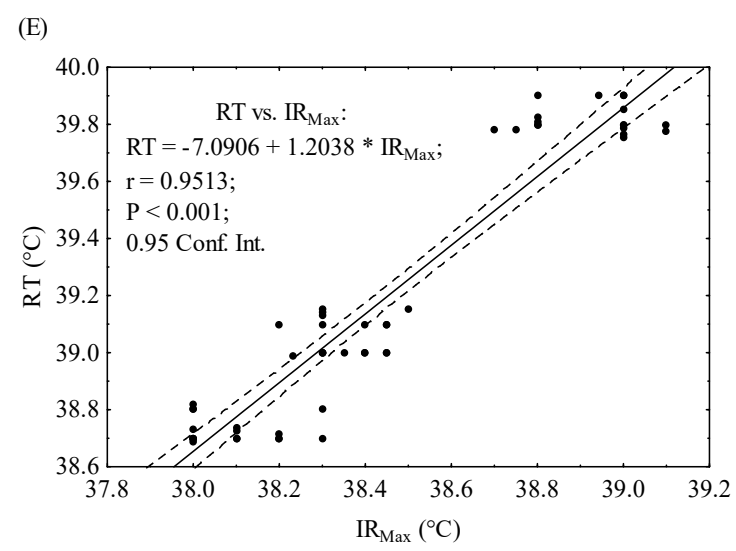

FIGURE 3. Correlation between of the rectal temperature (RT) and: (A) temperature of the ocular globe (PT); (B) head temperature (HQ); (C) shoulder temperature (ST); (D) hindquarters temperature (HQ); and (E) maximum infrared temperature (IR $\mathrm{Max})$.

\section{Agreement between of the methods}

In Figure 4, the relation of the discrepancies between the measurements obtained by the methods evaluated by applying the $t$ test for paired samples is shown, where it can be seen that there was no agreement between the data obtained by rectal thermometry and the data obtained by

(A)

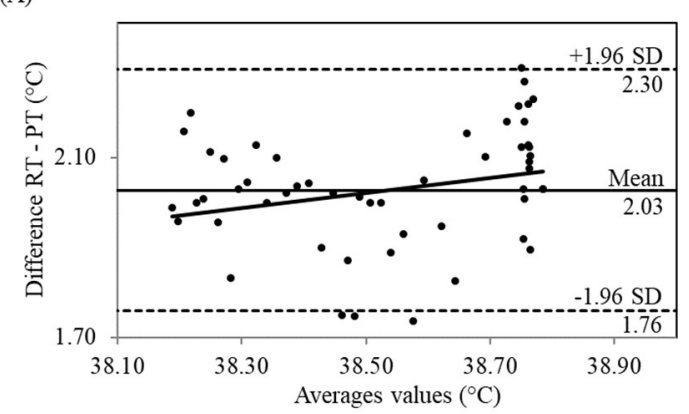

(C)

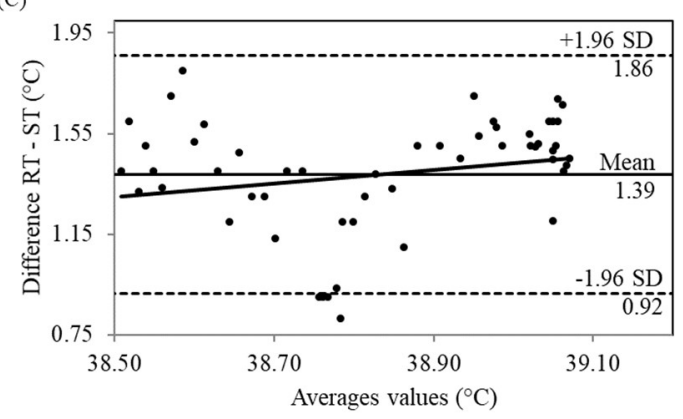

thermography infrared, in the regions of the ocular globe (PT), the head (HT), the shoulder (ST), the hindquarter $(\mathrm{HQ})$ and the maximum infrared temperature $\left(\mathrm{IR}_{\mathrm{Max}}\right)$, with a statistically significant difference $(\mathrm{P}<0.05)$ between the methods, which presented bias equal to $2.03,1.35,1.39$, 1.38 and 0.75 , respectively, for the differences between RT and PT, HT, ST, HQ and IR Max.

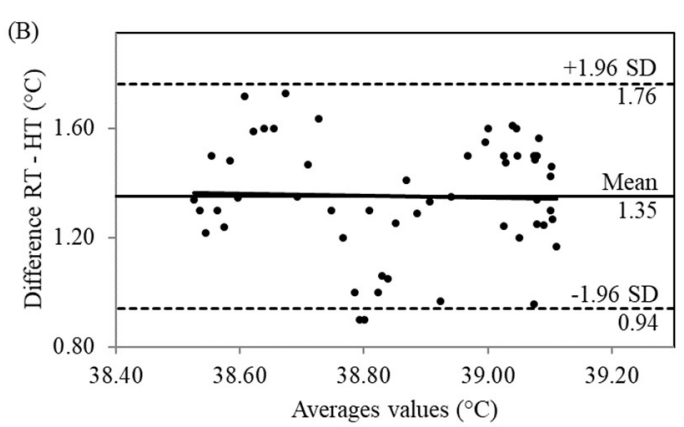

(D)

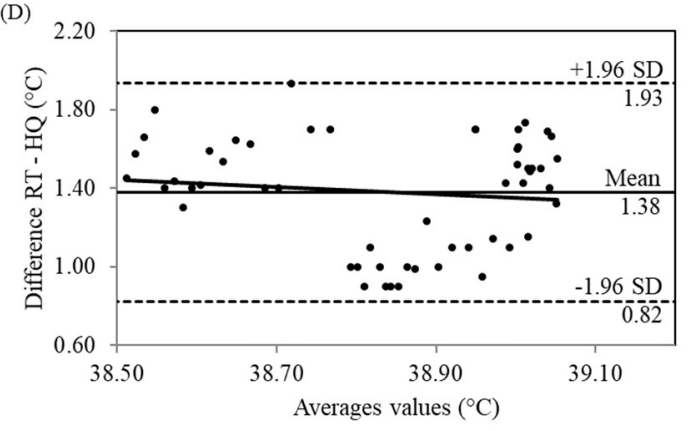

(E)

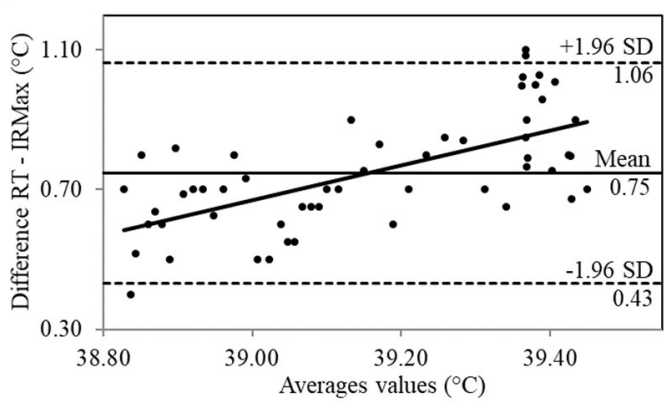

FIGURE 4. Analysis of agreement between rectal temperature data (RT) and: (A) ocular globe temperature (PT); (B) head temperature (HT) (C) shoulder temperature (ST); (D) hindquarter temperature (HQ); and (E) temperature maximum infrared $\left(\mathrm{IR}_{\mathrm{Max}}\right)$; SD: standard deviation. 
Analyzing the spatial distribution of the points in the diagrams (Figure 4) through the analysis of the correlation between the bias and the averages of the measures, it can be noted that in the cases of differences between RT-PT, RTHT, RT-ST and RT-HT the correlation with their respective means are null, with the slope of the correlation line significantly equal to zero $(\mathrm{P}=0.06,0.81,0.12$ and 0.41 , for the respective correlations), and it can be concluded that these biases are systematic. Therefore, although the measurements are not in agreement, the values of PT, HT, ST and HQ can be used to estimate the RT, as long as their values are added to their respective biases.

When analyzing the agreement between RT and $I_{\mathrm{Max}}$, it is found that among the evaluated agreements, this
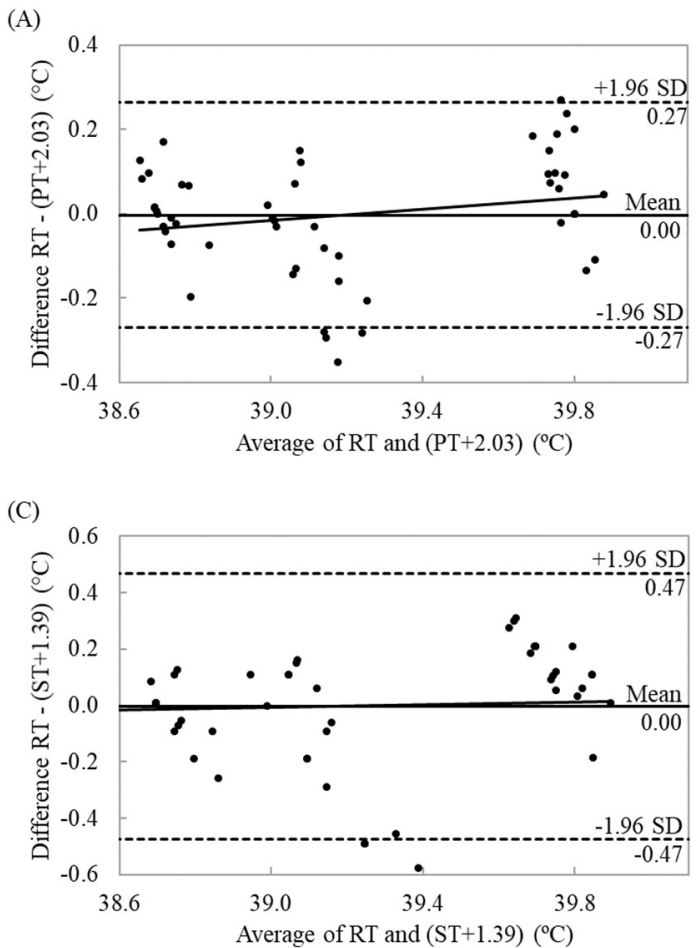

is the one that presents the bias (difference between the measures) closest to zero (0.75), but it is also verified that the bias is correlated significantly $(\mathrm{P}<0.05)$ with the averages of the measurements, thus, the difference observed between the values of RT and $\mathrm{IR}_{\mathrm{Max}}$, depends on the amount of data collected, which may lead to the occurrence of random errors and inaccuracies in the estimate of RT.

The Figure 5 shows the analysis of agreement between the RT values and the PT, HT, ST and HQ data, added with their respective biases. It can be noted that the methods have strong concordances, with biases values statistically equal to zero $(\mathrm{P}=0.11,0.37,0.75$ and 0.46 , for $\mathrm{PT}, \mathrm{HT}, \mathrm{ST}$ and $\mathrm{HQ}$, respectively) between the evaluated methods.

(B)

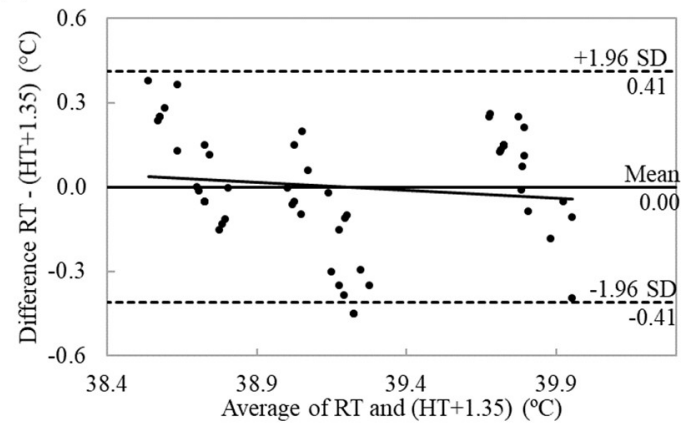

(D)

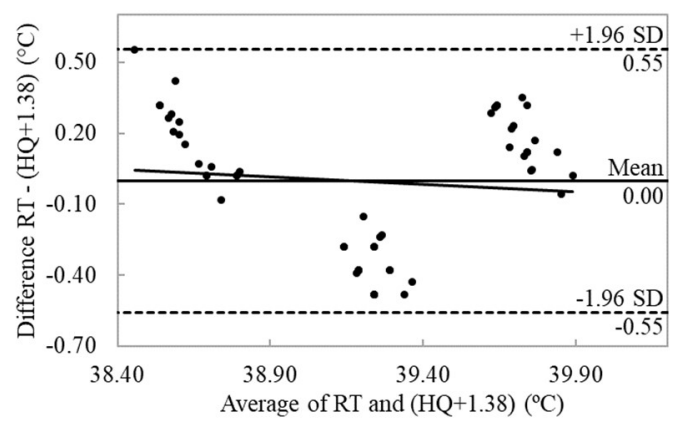

FIGURE 5. Agreement between rectal temperature (RT) and: (A) ocular globe temperature (PT); (B) head (HQ); (C) shoulder (ST); and (D) hindquarters (HQ), added of their respective biases; SD: standard deviation.

When subjected to environments with air temperatures above the thermoneutral zone, homeothermic animals employ several thermoregulatory mechanisms to compensate for heat gain, per equivalent loss, and maintain internal body temperature within narrow limits of variation and achieve thermal equilibrium (McKinley et al., 2017). The present study shows that PT, HT, ST, HQ and IR Max increased $(\mathrm{P}<0.05)$ according to the elevation of the air temperature, suggesting that this fact is due to the significant increase $(\mathrm{P}<0.05)$ in the body core representative temperature (RT) as a function of the heat generation due to the metabolic reactions and the reduction of the thermal gradient between the animal and the environment, which reduces the ability of the animals to dissipate heat in a sensitive way, being this a primary physiological mechanism responsible for the dissipation of body core heat through the bloodstream to the peripheries and subsequently to the environment (Rizzo et al., 2017).

Body core temperature is a good measure of heat tolerance in homeothermal animals, and its variation represents the result of all the processes of gaining and losing body heat (Marques et al., 2021). Goats are known among ruminants, for their ability to tolerate high air temperatures, due to their ability to reduce metabolic activities, preventing body temperature from increasing during heat stress, reducing the risk of death for the animals, but causing falling productivity (Marques et al., 2021). When observing the behavior of the RT values of the animals evaluated in the present research, it can be noted that despite the significant increase of the same, due to the increase in air temperature, its values remained within the range considered normal for the species, which according to Souza et al. (2008), is located between the temperatures of 38.6 and 39.9 ${ }^{\circ} \mathrm{C}$, showing the rusticity of these animals in the face of adversities, environmental caused by high air temperatures.

The observation of skin and eye temperature has long been used as a less invasive means of detecting changes in body temperature in production animals (Wijffels et al., 2021). The use of infrared radiation to measure body surface and eye temperature has been investigated for numerous applications, including infection, reproductive status, feed efficiency, and stress (McManus et 
al., 2016). Due to direct interaction with the environment, external body surface temperatures are lower than core temperatures (rectal, vaginal, rumen) and exhibit greater variability (Church et al., 2014). Skin and surface temperature locations can be expected to be different due to variable blood flow and the structure of the subcutaneous tissue (Taylor et al., 2014). Eye temperature is consistently closer to core temperature and shows the least variability relative to other locations in the body (Marques et al., 2018).

In the three thermal conditions evaluated, it was possible to observe the higher surface temperature ( $\left.\mathrm{IR}_{\mathrm{Max}}\right)$ in the inferior mucosal region of the animals' eyes, and this fact can be justified by the existence of thinner layers of skin and greater vascularization of this region, when compared to other evaluated regions (Rizzo et al., 2017). The areas around the eye, especially around the posterior border of the eyelid and lacrimal caruncle, have a rich capillary vascularization that responds sensitively to changes in blood flow resulting from changes in the internal temperature of the animal (Elias et al., 2021).

While eye temperature is a common choice in many studies, the suitability of other sites for IR are still under active investigation. IR estimates of eye temperature or the temperature at other sites and their correlations with concurrent core temperature and/or meteorological variables or bioclimatic indices, has produced variable results (Wijffels et al., 2021). All the surface temperatures evaluated (PT, HT, ST, HQ and $\mathrm{IR}_{\mathrm{Max}}$ ) correlated significantly $(\mathrm{P}<0.05)$ with the rectal temperature showing that these are sensitive responses and can detect with a high degree of precision the changes in body core temperature of the goats when submitted to thermal stress conditions. In addition, based on the results presented in Figure 3, it can be observed that the temperature of PT and IR $\mathrm{Iax}_{\text {pax }}$ presented a higher correlation with RT than the other surface temperatures (HT, ST and HQ), with Pearson correlation coefficient of $r=0.956$ and 0.951 , respectively.

The application of infrared thermography to identify the comfort and heat stress conditions of production animals is of increasing importance. However, the skin temperature of animals can be influenced by several external and internal factors, such as race, color, season and climatic conditions (Wijffels et al., 2021). Despite the limitation of data obtained by the IR technique to reflect core body temperature, it is still practical for early assessment of heat stress as it is easy to use and requires minimal labor compared to measuring RT (Peng et al., 2019). According to Steck et al. (2011) the replacement of the rectal thermometry method with non-invasive methods for the measurement of thermal stress is potentially beneficial, since it dispense the direct contact of the evaluator with the animal, avoiding external influences, which may mask the results. Based only on the analysis of the correlations we have that the RT of the goats can be measured accurately and remotely through the $\mathrm{PT}$ and $\mathrm{IR}_{\mathrm{Max}}$ temperatures.

The correlation coefficient cannot be used alone to evaluate the relationship between two methods since it does not provide an indication of the equality discrepancy between the data values. Second, the correlation coefficient does not reveal information about the presence of a systematic difference between the methods (van Stralen et al., 2008).
The surface temperatures at the points collected did not show agreement with the RT, however with the exception of $\mathrm{IR}_{\mathrm{Max}}$, it can be seen that the biases did not correlate significantly with the averages of the measurements and, despite significant differences between the methods evaluated (ie, PT, HT, ST and HQ did not reproduce values statistically equal to RT), they show the same behavior, keeping the error statistically constant, even with the increase in air temperature.

The RT can be estimated accurately, through the responses $\mathrm{PT}, \mathrm{HT}, \mathrm{ST}$ and HQ, as long as its measurements are increased by the respective biases, and the RT can be represented by any of the following mathematical expressions: $\mathrm{RT} \cong \mathrm{PT}+2.03 ; \mathrm{RT} \cong \mathrm{HT}+1.35 ; \mathrm{RT} \cong \mathrm{ST}+$ 1.39 ; or $\mathrm{RT} \cong \mathrm{HQ}+1.38$, with statistically insignificant mean errors. Also observing the limits of agreement between the RT measurements and the estimated averages based on surface temperatures, such estimates have a high level of precision, and there may be errors in estimates ranging from $\pm 0.27, \pm 0.41, \pm 0.47$ and $\pm 0.55^{\circ} \mathrm{C}$, for PT, HT, ST and HT, respectively, highlighting the expression $\mathrm{RT} \cong \mathrm{PT}+2.03$, as it has a smaller range of error variation.

Observing the Bland-Altman diagram presented in Figure 4E that deals with the analysis of agreement between the RT and $\mathrm{IR}_{\text {Max }}$ measurements, it can be seen that in the air temperatures between the range of 26 and $30{ }^{\circ} \mathrm{C}$ the error value (difference) between the methods was approximately $0.7{ }^{\circ} \mathrm{C}$ for both air temperatures, however when the air temperature increased to $34{ }^{\circ} \mathrm{C}$, the average error increased to $0.9^{\circ} \mathrm{C}$, thus causing the significant correlation between the bias and the averages of the methods' measures, which reflects in the consequent increase in the error between the readings, according to the elevation of the air temperature, being the $\mathrm{IR}_{\mathrm{Max}}$ therefore, inadequate for the prediction of the RT of goats in conditions of thermal stress.

\section{CONCLUSIONS}

It is possible to estimate the rectal temperature (RT) of crossbred Boer goats accurately, about six months old, based on the surface temperatures of the ocular globe (PT), head (HT), shoulder (ST) and hindquarter (HQ) of the animals, being the region most suitable for this, according to the results of the present research, the region of the ocular globe that presented Pearson's correlation coefficient of 0.956. Another fact that makes this estimate feasible is that although none of the surface temperatures have shown agreement with the RT, the error values in the estimates showed a statistically constant behavior (with the exception of $\operatorname{IR}_{\mathrm{Max}}$ ), as the air temperature increased. Thus, it was possible to accurately estimate the RT values through the values of PT, HT, ST and HQ added to their respective biases, with PT also standing out in this criterion for presenting lower errors $\left( \pm 0.27^{\circ} \mathrm{C}\right)$ in the estimates.

\section{ACKNOWLEDGMENTS}

To the National Council for Scientific and Technological Development (CNPq) for the scholarship granted and research funding Process N. 445393/2014-9. 


\section{REFERENCES}

Byrne DT, Berry DP, Esmonde H, McHugh N (2017) Temporal, spatial, inter-, and intra-cow repeatability of thermal imaging. Journal of Animal Science 95(2):970979. DOI: https://doi.org/10.2527/jas.2016.1005

Church JS, Hegadoren PR, Paetkau MJ, Miller CC, RegevShoshani G, Schaefer AL, Schwartzkopf-Genswein KS (2014) Influence of environmental factors on infrared eye temperature measurements in cattle. Research in Veterinary Science 96(1):220-226. DOI: https://doi.org/10.1016/j.rvsc.2013.11.006

Elias B, Starling M, Wilson B, McGreevy P (2021) Influences on Infrared Thermography of the Canine Eye in Relation to the Stress and Excite of Racing Greyhounds. Animals 11(1):1-16. DOI: https://doi.org/10.3390/ani11010103

Ferreira EB, Cavalcanti PP, Nogueira DA (2013) ExpDes.pt: experimental designs pacakge (Portuguese). R package version 1.1.2.

George WD, Godfrey RW, Ketring RC, Vinson MC, Willard ST (2014) Relationship among eye and muzzle temperatures measured using digital infrared thermal imaging and vaginal and rectal temperatures in hair sheep and cattle. Journal of Animal Science 92(11):4949-4955. DOI: https://doi.org/10.2527/jas.2014-8087

Lopes Neto JP, Marques JI, Furtado DA, Lopes FF de M, Borges VP, Araújo TGP (2018) Pupillary stress index: A new thermal comfort index for crossbred goats. Revista Brasileira de Engenharia Agrícola e Ambiental 22(12):866-871. DOI: https://doi.org/10.1590/18071929/agriambi.v22n12p866-871

Marques JI, Lopes Neto JP, Nascimento JWB, Talieri IC, Medeiros GR, Furtado DA (2018) Pupillary dilation as a thermal stress indicator in boer crossbred goats maintained in a climate chamber. Small Ruminant Research 158(1):26-29. DOI: https://doi.org/10.1016/j.smallrumres.2017.11.013

Marques JI, Leite PG, Lopes Neto JP, Furtado DA, Borges VP, Sousa WS (2021) Estimation of heat exchanges in Boer crossbred goats maintained in a climate chamber. Journal of Thermal Biology 96(2021) 102832. DOI: https://doi.org/10.1016/j.jtherbio.2020.102832

McKinley M, Trevaks D, Weissenborn F, McAllen R (2017) Interaction between thermoregulation and osmoregulation in domestic animals. Revista Brasileira de Zootecnia 46(9):783-790. DOI:

https://doi.org/10.1590/S1806-9290201700090001
McManus C, Tanure CB, Peripolli V, Seixas L, Fischer V, Gabbi AM, Menegassi SRO, Stumpf MT, Kolling GJ, Dias E (2016) Infrared thermography in animal production: an overview. Computers and Electronics in Agriculture 123:10 16. DOI: https://doi.org/10.1016/j.compag.2016.01.027

NRC - National Research Council (2007) Nutrient requeriments of small ruminants: sheep, goats, cervids, and new world camelids. NRC.

Peng D, Chen S, Li G, Chen J, Wang J, Gu X (2019) Infrared thermography measured body surface temperature and its relationship with rectal temperature in dairy cows under different temperature-humidity indexes. International Journal of Biometeorology 63(2019):327336. DOI: https://doi.org/10.1007/s00484-018-01666-X

Rizzo M, Arfuso F, Alberghina D, Giudice E, Gianesella M, Piccione $G$ (2017) Monitoring changes in body surface temperature associated with treadmill exercise in dogs by use of infrared methodology. Journal of Thermal Biology 69: 6468. DOI: https://doi.org/10.1016/j.jtherbio.2017.06.007

Sejian V, Bhatta R, Gaughan JB, Dunshea FR, Lacetera N (2018) Review: Adaptation of animals to heat stress. Animal 12(S2):431-444. DOI: https://doi.org/10.1017/S1751731118001945.

Souza BB, Souza ED, Silva RMN, Cezar MF, Santos JRS, Silva GA (2008) Respostas fisiológicas de caprinos de diferentes grupos genéticos no semi-árido paraibano. Ciência e Agrotecnologia 32(1):314-320. DOI: https://doi.org/10.1590/S1413-70542008000100045

Steck LN, Sparrow EM, Abraham JP (2011) Non-invasive measurement of the human core temperature. International Journal of Heat and Mass Transfer 54(4):975-982. DOI: https://doi.org/10.1016/j.ijheatmasstransfer.2010.09.042

Steketee J (1973) Spectral emissivity of skin and pericardium. Physics in Medicine \& Biology 18(5):686-694. DOI: https://iopscience.iop.org/article/10.1088/0031-9155

Taylor NAS, Tipton MJ, Kenny GP (2014) Considerations for the measurement of core, skin and mean body temperatures. Journal of Thermal Biology 46(2014):72101. DOI: https://doi.org/10.1016/j.jtherbio.2014.10.006

van Stralen KJ, Jager KJ, Zoccali C, Dekker FW (2008) Agreement between methods. Kidney International 74(9):1116-1120. DOI: https://doi.org/10.1038/ki.2008.306

Wijffels G, Sullivan M, Gaughan John (2021) Methods to quantify heat stress in ruminants: Current status and future prospects. Methods 186(2021):3-13. DOI: https://doi.org/10.1016/j.ymeth.2020.09.004 